\title{
VERSATILITY OF INTRAORAL MAXILLARY BUCCAL SULCUS APPROACH FOR SURGICAL MANAGEMENT OF UNILATERAL DISPLACED ZYGOMATIC COMPLEX FRACTURES
}

\author{
Emad F. Essa* and Ibrahim M. Nowair*
}

\begin{abstract}
Purpose: The aim of this research was to evaluate the versatility of using intraoral maxillary buccal sulcus approach for reduction of zygomatic complex fractures and also for rigid fixation of the infraorbital horizontal buttress.

Patients and methods: Twenty patients with displaced zygomatic complex fractures were diagnosed according to signs, symptoms and radiographically, treated by open reduction and internal fixation. The data were recorded and analyzed.

Results: The intraoral approach has several advantages such as (a) only one incision is necessary to approach the zygomatico-maxillary buttress and infraorbital rim, (b) it decrease surgical time (c) it avoids periorbital scars and (d) avoidance of lower lid ectropion or entropion.
\end{abstract}

KEY WORDS: Zygomatic complex fractures, intraoral approach, open reduction and internal rigid fixation

\section{INTRODUCTION}

Zygomatic bone plays a vital role in maintaining facial contour. This is because the facial contour is directly influenced by underlying bony architecture ${ }^{1}$. Fracture and displacement of this bone not only causes cosmetic defects but also disrupts ocular and mandibular functions ${ }^{2}$.

Fractures can involve any of the four articulations of zygoma which include zygomatico-maxillary, zygomatico-temporal, zygomatico-frontal and zygomatico-sphenoidal. Fractures involving zygomatic bone should be repaired at the earliest period because it can cause both The zygomatic bone is a strong buttress of the lateral portion of the middle third of the facial skeleton lying between the zygomatic processes to the frontal bone and the maxilla. Due to its prominent position, it is frequently fractured, alone or along with other bones of the mid-face. Direct blows usually first strike on the most prominent part which is the malar eminence. This causes disruption at the relatively weaker parts

\footnotetext{
* Lecturer, Oral \& Maxillofacial Surgery, Faculty of Dentistry, Tanta University, Egypt.
} 
which are the zygomatic arch, the frontal process, and the zygomatico-maxillary suture ${ }^{4}$.

The clinical signs and symptoms are related to displacement or rotation of the fragments includes enophthalmos, orbital dystopia, proptosis, diplopia, trismus, depressed malar prominence, and hypoesthesia ${ }^{5-6}$.

Similarly, it is important to recognize that zygomatic complex fractures have been associated with paraesthesia (52.2\%), trismus (47.3\%), diplopia $(8.3 \%)$ and malocclusion $(5.3 \%)$ in the preoperative period. Therefore, prompt recognition and treatment of the injury is important to decrease any potential long term squelae ${ }^{7}$.

The diagnosis of fractured zygoma can usually be made with thorough clinical examination and adequate radiological evaluation. Plain radiograph commonly used in mid-facial fractures is occipito-mental or Water's view which can clearly demonstrate the bone discontinuity in the zygomatico-maxillary buttress and the inferior orbital rim. The submento-vertex view more clearly detects fractures of the zygomatic arch ${ }^{6}$.

CT scan and its three-dimensional applications are indicated for visualization of the orbit if the orbital portion of the zygomatic fracture is suspected. Once the diagnosis is established a surgical treatment plan can be made, as the current principle of treatment of maxillofacial fracture is open reduction and rigid fixation ${ }^{6}$.

Open reduction of these fractures allows for the gross confirmation of the reduction of the fracture site and rigid fixation ${ }^{8}$. However, open reduction can lead to undesirable complications such as ectropion, facial nerve injury and dropping of the cheek owing to extensive dissection of the periosteum ${ }^{9,10}$. Moreover, as maxillo-facial fractures frequently occur in young persons, the facial incisions can be a burden to surgeons and patients due to unsightly postoperative scars. In the same way, metal plates and screws used for fixation may require removal at a later date, translating into further surgery, which could potentially increase scarring ${ }^{11,12}$.

Many kinds of surgical approaches can be used and each of them has its advantages and disadvantages. Amount of exposure, skin scars and technical difficulty must be considered. Functional and aesthetics defects of the lower eyelid may happen when the transconjunctiva and subciliary approaches are needed ${ }^{13}$. The bicoronal approach also may cause sensorial and motor disturbance ${ }^{14,15}$,

The intraoral approach to zygomatic fracture treatment was introduced by Keen in 1909. This technique allows both an adequate visualization of the zygomatico-maxillary buttress and intraoral reduction of zygomatic bone and zygomatic arch fractures. Similar techniques have been published over the last 30 years ${ }^{16}$.

\section{AIM OF WORK}

The aim of this research was to evaluate the versatility of using modified intraoral maxillary buccal sulcus (Keen) approach for both reduction and fixation of zygomatic complex fractures.

\section{MATERIALS AND METHODS}

This study was conducted on twenty patients aged between 16 and 55 years with isolated zygomatic bone fractures, were selected from outpatient clinic of Oral and Maxillofacial Surgery Department, faculty of dentistry as well as from Tanta Emergency Hospital, Tanta University.

Patients who fulfilled the inclusion criteria of displaced ZMC fractures as restricted mouth opening, loss of cheek prominence, malar depression and patients with paraesthesia of the infra orbital nerve or diplopia were enrolled.

Patients with comminuted, infected zygomatic bone fracture, gunshot injuries, medically unfit for surgery, unfit to undergo general anesthesia as evident from pre-operative anesthetic evaluation were excluded from this study. 
History was taken from the patient to determine the cause of fracture. Complete physical examination of the traumatized patient zygomatic bone was done to know the sites of fracture and confirmed by axial, coronal and three-dimensional reformatting of computed tomography that allow more predictable preoperative planning.

After clinical and radiological examinations, the sites of fracture were determined using CT scan Fig (1). All patients that requiring reduction and internal rigid fixation for three point mini plate osteosynthesis were carried out under general anesthesia using nasal endotracheal intubations.

The procedure was explained to the patients. Informed written consent was signed by the patient and/or their relatives. Preoperative antibiotics and all other routine preparations for general anesthesia were done.

The signs and symptoms were recorded and it was observed that $66.7 \%$ of the patients were complaining from paraesthesia of the infraorbital nerve, $90 \%$ had subconjunctival hemorrhage and circumorbital ecchymosis Fig. (2) and 10\% were complaining from diplopia. Step deformity of the infraorbital rim was found in $85 \% \%$ of the cases and flatness of the cheek was noted in all patients

Two types of approaches were used for treatment including lateral eyebrow incision Fig. (3) and modified intraoral maxillary buccal sulcus (Keen) incision Fig. (4).

Fractures of zygomatic bone were reduced directly by elevation from the intraoral approach by exposing fracture sites and fixation with $1.5 \mathrm{~mm}$ osteosynthesis plating system and screws of $7 / 9$ $\mathrm{mm}$ at three points, the zygomatic frontal region (straight plate), zygomatico maxillary region (three dimension L- shape) and at the infraorbital horizontal buttress region (straight plate) Fig. $(\mathbf{5 , 6})$.

The time that was taken to expose the fractured infraorbital rim and reduction of the ZCF was ranged between $8 \mathrm{~min}$ to $20 \mathrm{~min}$ with a mean of $10 \mathrm{~min}$

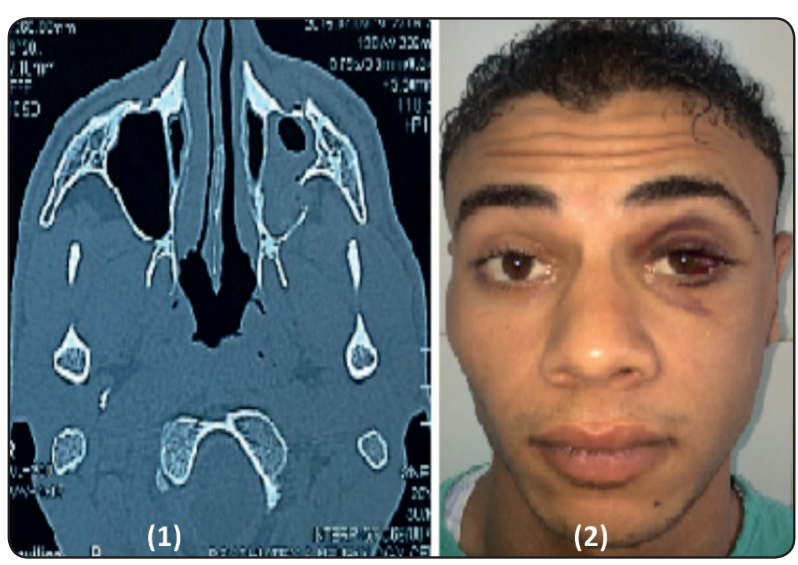

Fig. (1): Axial CT showing displaced lt ZCF. Fig. (2): Clinical photograph showing lt subconjunctival hemorrhage

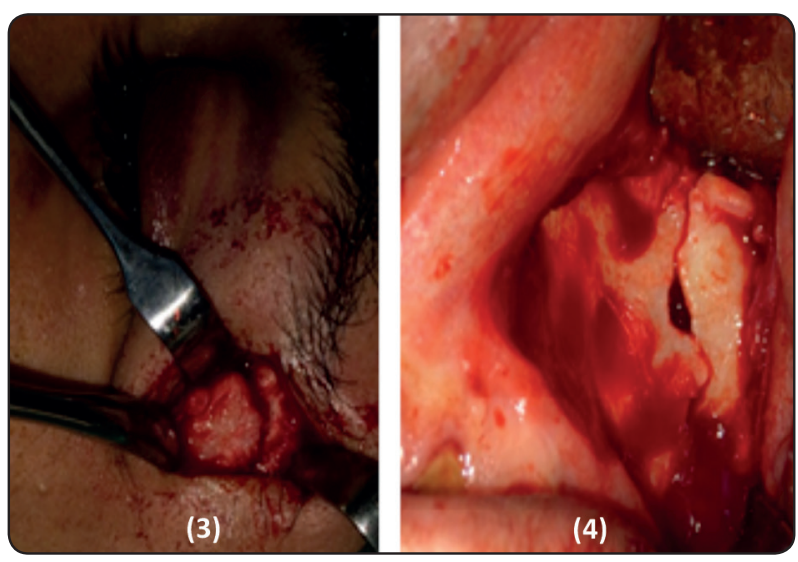

Fig. (3): Clinical photograph showing lt eyebraw incision. Fig. (4): Clinical photograph intraoral buccal sulcus incision

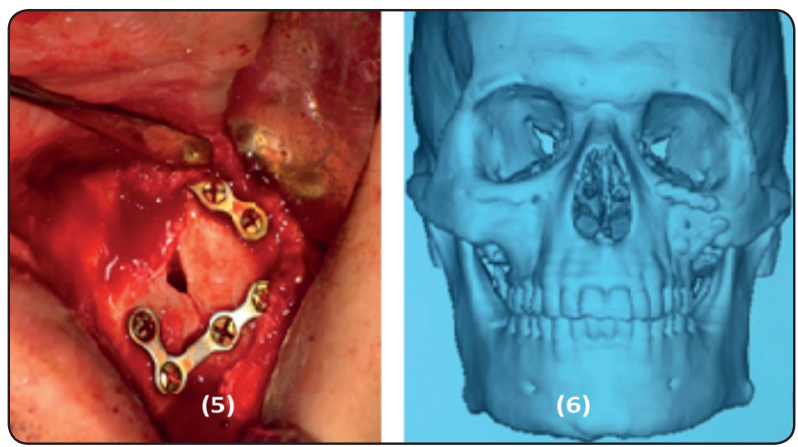

Fig. (5): Intraoperative photograph showing intraoral fixation of ZCF. Fig. (6): Postoperative photo-radiograph showing three points fixation of lt ZCF. 
All patients were followed up postoperatively for a period of nine months.

\section{Evaluation points}

1- Reduction criteria: This was tested via:

a) Audible click during reduction

b) Visible improvement in cheek prominence

c) Normal contour of three buttresses.

d) Normal contour of infraorbital foramen

2- Mouth Opening: Assessed by measuring the interincisal distance using a calibrated metallic scale

3- Binocular Diplopia if present: This was evaluated by holding a finger at an arm's length in front of the patient's eye and asking the patient to report double vision as the finger was moved in each of the nine positions of the gaze.

4 -Infraorbital Nerve Paraesthesia: It was evaluated by performing the cotton wisp and pin prick test at each of the follow up periods.

5- Step deformity and depression over the cheek: This was elicited by palpation at each of the follow up periods.

6- Patient satisfaction with aesthetic and functional outcomes

Postoperative radiographs were taken and the clinical and radiographic data were recorded and analyzed.

\section{RESULTS}

A total of twenty patients were followed up for an average of nine months after open reduction and internal rigid fixation of their ZMC fractures.

The age group of the patients was varied from 16 to 55 years with the mean of 30 years.

The highest incidence of fracture was seen between the age group of 20 to 35 years.
Seventeen (85\%) patients were male and three $(15 \%)$ patients were female. twelve $(60 \%)$ patients had left side ZCF and eight (40\%) had right sided ZCF fractures.

Road traffic accident was found to be the most common etiology of ZCF accounting for $85 \%$ seventeen patients followed by $10 \%$ two patients due to fall and $5 \%$ one patient due to inter personal violence.

All patients were operated at time interval between two days and two weeks post trauma with a mean of seven days.

The clinical signs and symptoms were reevaluated and all patients showed satisfactory facial symmetry, there was a gradual improvement in sensation of infra orbital nerve paraesthesia with restoration of normal sensation in all patients at the end of the second month.

Regarding the contour of the infraorbital rim, there was no relapse. Also the cheek prominence shows no flatness at follow up periods.

All patients show adequate eye functions in all nine positions gaze without diplopia at the whole follow up periods.

The recorded preoperative interincisal mouth opening was ranged between $15-30 \mathrm{~mm}$ (mean opening was $25 \mathrm{~mm}$ ) which improved after reduction and fixation from $38-44 \mathrm{~mm}$ with a mean of $42 \mathrm{~mm}$.

Primary healing of both eye brow and modified intraoral maxillary buccal sulcus incisions were obtained in all cases. There were no complications of maxillary sinus fistulae or infection detected during the whole follow up periods.

All patients were satisfied with the results obtained regarding esthetics as the lower lid of the affected side was similar to the normal side and the eyebrow scar was invisible. All patients were satisfied regarding functional results obtained after reduction and fixation of the $\mathrm{ZCF}$. 


\section{DISCUSSION}

Facial asymmetry due to any injury leads to social and psychological discomfort of patients. So, surgical treatment to restore the function, form, and aesthetics becomes a necessity. The susceptibility of zygomatic fractures is explained by Dawson 1953 as the most common facial fracture Ebenezer et al $2014^{17}$.

Nysingh $\mathbf{1 9 6 0}^{18}$ stated that zygomatic fractures are second in frequency after nasal fractures.

As mentioned by Grey et $\mathbf{a l . 1 9 9 3}{ }^{19}$, delayed retro-bulbar hemorrhage and transient blindness can be the result of ZCF fractures so, ophthalmic opinion is mandatory in most of the ZCF. In our study, ophthalmic evaluation was done for all patients.

Many treatment modalities have been proposed for zygomatic complex fractures. The principle of zygomatic complex fractures management involves the reduction of fractured fragments to their normal anatomic relationship for adequate bony contact and alignment Ebenezer et al 2014 ${ }^{17}$.

We have applied modified keen's intra oral approach to reduce and/or elevate the fractured zygomatic complex.

In our study we recorded that males were subjected to zygomatic complex fractures more than females, we thought that the reason could be greater social and economic involvement of adult males.

The etiology of ZCF in our research shown high percentage $(85 \%)$ from road traffic accident, Similar to that reported by Chowdhury and Menon $\mathbf{2 0 0 5}^{2}$ $86.20 \%$, Fasola et al $2001^{20} 81.6 \%$, Obuekwe et al $\mathbf{2 0 0 5}^{21} 81 \%$.

Keen $1909^{22}$ advised an intra-oral approach to reduce the fracture, which has been reviewed by various authors. We followed this approach for reduction in all patients.
The time elapsed during ZCF reduction was comparable with that reported by Balasubramaniam et al $\mathbf{2 0 1 3}^{23}$ who stated that less force was required with this technique for elevation as compared to extra-oral approach and intra-oral approach can be performed in minutes in addition scar alopecia was absent with intraoral approach.

Balasubramanian et al $\mathbf{2 0 1 3}^{23}$ discussed the various management options available to treat the fractured zygoma. They treated 82 patients for a period of 3 years (2010-2012). They stated that two point fixation is sufficient in a majority of patients. Fixation was done at fronto - zygomatic region and infra orbital region. Lee et al $\mathbf{2 0 0 6}^{24}$ also stated that mini plate fixation at the infra orbital rim and fronto zygomatic suture region would provide significant amount of stability. However, in our study three point fixation were applied to obtain the maximum stability.

In all cases of our research, we have used the lateral eyebrow approach to expose the fracture in the zygomatico-frontal suture region. After exposing the fracture, the fragments were aligned and fixed with $1.5 \mathrm{~mm}$ mini plates and screws of 7 or $9 \mathrm{~mm}$ length without any complication, this was in agreement with Michael and Michael $1990{ }^{25}$ who presented the report of an anatomic study of 20 adult skulls to place the screws above the fronto zygomatic suture, they was found that $6-8 \mathrm{~mm}$ screws can be safely placed at the zygomatico frontal suture region with no complication.

There was excellent exposure of the fracture site, infra orbital nerve and reduction of ZCF at a minimum time which was in agreement with Srivastava et al $\mathbf{2 0 1 1}^{26}$ who stated that when used the buccal sulcus approach for reduction of ZCF the Minimum time taken for the surgery was 4 minutes.

The stability of the reduced and fixed ZCF at the follow up periods did not changed this was accepted with the studies of Apfelberg $1977{ }^{27}$, Schnetler $\mathbf{1 9 9 0}^{28}$ and Mitchell et al $1995{ }^{29}$, who reported that 
adequate reduction by the intraoral approach could be achieved when the ZCF is uncomplicated and treated within few days after trauma.

All patients of our study were satisfied with the results after reduction and fixation of the ZCF; this was because of adequate reduction, good facial contour and early recovery of the infraorbial nerve paraesthesia.

The advantages of using only two incision lines; eye brow and intraoral approach were less time to expose the fracture lines at the infraorbital rim with anatomical reduction of fracture segments intraoperative, reliable method for three points fixation which provide three dimensional stability.

\section{CONCLUSION}

From this study, it can be concluded that reduction and fixation of $\mathrm{ZCF}$ with three points fixation can be obtained with only two incisions, also intraoral maxillary buccal sulcus approach allow wide exposure for reduction and fixation of the infraorbital rim in ZCF.

\section{REFERENCES}

1- Edward E, Winai K (1996) Analysis of treatment of the isolated zygomaticomaxillary complex fractures. J Oral Maxillofac Surg 54(4):386-400

2- Chowdhury SKR, Menon PS(2005): Etiology and management of zygomatico maxillary complex fractures in the armed forces. MJAFI, 61:238-240.

3- Nayyar M,S(2002): Management of zygomatic complex fracture. J Coll Physicians Surg Pak,12:700-705.

4- Kaastad E, Freng A. (1989): Zygomatic-maxillary fractures. J Craniomaxillofac Surg; 17:210.

5- Peterson L. (1993): Contemporary oral and maxillofacial surgery. 2nd ed. St. Louis: Mosby; p. 597.

6- Booth P.W, Schendel S.A, Hausamen J.E. (2007): Maxillofacial surgery. 2nd ed. St. Louis, Missouri: Churchill Livingstone;. p. 104-19, 120-54.

7- Hwang. K and Kim D. H., (2011): “Analysis of Zygomatic Fractures, Journal of Craniofacial Surgery, Vol. 22, No. 4, pp. 14161421.
8- Hwang. K. (2010): One-Point Fixation of Tripod Fractures of Zygoma through a Lateral Brow incision, Journal of Craniofacial Surgery, Vol. 21, No. 4, pp. 1042- 1044.

9- Kaufman Y., Stal D., Cole P., et al.,(2008): Orbitozygomatic Fracture Management, Plastic and Reconstructive Surgery, Vol. 121, , pp. 1370-1374.

10- Park B. Y., Song S. Y., Yun I. S., Lee D. W., Rah D. K. and Lee, W. J. (2010):First Percutaneous Reduction and Next External Suspension with Steinmann Pin and Kirschner Wire of Isolated Zygomatic Fractures, Journal of Craniofacial Surgery, Vol. 21, No. 4, , pp. 1060-1065.

11 - Kim S. T., Go D. H., Jung J. H., Cha H. E., Woo J. H. and Kang I. G., (2011): Comparison of 1-Point Fixation with 2-Point Fixation in Treating Tripod Fractures of the Zygoma, Journal of Oral and Maxillofacial Surgery, Vol. 69, No. 11, pp. 2848-2852.

12- Chrcanovic B. R., Cavalcanti Y. S. and Reher P., (2009): Temporal Miniplates in the Frontozygomatic Area ,An Anatomical Study, Journal of Oral and Maxillofacial Surgery, Vol. 13, , pp. 201-206.

13- Wilson, S. \& Ellis, E (2006): Surgical approaches to the infraorbital rim and orbital floor, the case for the subtarsal approach. J. Oral Maxillofac. Surg., 64(1):104-7,

14- Al-Kayat, A. \& Bramley, P. A (1979): Modified preauricular approach to the temporomandibular joint and malar arch. Br. J. Oral Maxillofac. Surg., 17(2):91- 103,

15- Zhang, Q. B.; Dong, Y. J.; Li, Z. B. and Zhao, J. H. (2006): Coronal incision for treating zygomatic complex fractures. J. Craniomaxillofac. Surg., 34(3):182-5,

16- Carvalho A. C. G. and Queiroz P.T,(2012): Intraoral Approach to Zygomatic Fracture: Modified Technique for Infraorbital Rim Fixation, J Craniofac Surg 2012;23: 537-538

17- Ebenezer V, Ramalingam B and Sivakumar M(2014): Treatment of Zygomatic Complex Fractures Using Two Point Fixation under General Anaesthesia. World Journal of Medical Sciences 10 (2): 179-183,

18- Nysingh, J.G., (1960): Zygomatico maxillary Fractures with a report of 200 consecutive cases. Arch Chir Neerl, 12: 157.

19- Gray B, P,. Leen M.M. and Loftus M.J., (1993): Late retro bulbar hemorrhage and blindness following malar fracture complicated by factor XI deficiency. Journal of oral and maxillofacial surgery 51:699-702. 
20- Fasola A.O, Obiechina A.E, Arotiba J.T(2001): An audit of midface fractures in Ibadin, Nigeria. Afr J Med Sci.; 30:183-86.

21- Obuekwe, Owotade F, Osaiyuwu O (2005): Etiology and pattern of zygomatic complex fractures; a retrospective study. J of National Medical Association;97:992-96

22- Keen, W.W., 1909. Surgery: Its principles and practice. Philadelphia: WB Saunders.

23- Balasubramanian T, (2013).: Seethalakshmi Narashiman, Karthikeyan Arjunan. Otolaryngology Journal, pp: 3.

24- Lee P.K, Lee J.H, Choi Y.S, Oh D. Y, Rhie J.W, Han K.T and Ahn S.T, (2006): J. Korean Med. Sci., 21: 1080-5.

25- Michael, F. Z and Jeffery, (1990):The placement of screws above the zygomatico-frontal suture. Journal of oral and maxillofacial surgery, 48: 813-816.

26- Srivastava A, Sharma R, Chandramala, R (2011): Versatility of buccal sulcus approach for zygomatic complex fractures; Journal of Dentistry July - Vol 2 Issue 3

27- Apfelberg, D.B., Lavey, E, Masen, M.R. (1977): Upper buccal sulcus approach for the reduction of zygomatic complex fractures. Journal of Trauma, 17;11:847-849.

28- Schnetler C.F.J(1990): “A technique for reducing fractures of the zygomatic complex under local anesthesia" Br. Journal of Oral and Maxillofacial surgery, 28:168-171.

29- Mitchell D.A and MacLeod S.P.R: "Multipoint fixation at the frontozygomatic suture with microplates: a technical note.'Int J of Oral and Maxillofacial Surg.1995, 24; 151-152. 